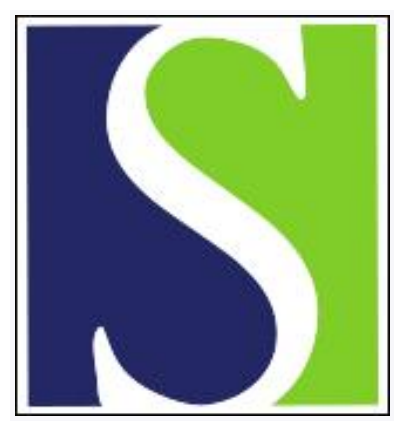

Scand J Work Environ Health 1986;12(4):313-319

https://doi.org/10.5271/sjweh.2137

Issue date: Aug 1986

Follow-up study of patients with vibration syndrome in Japan. by Nasu Y, Ishida K

This article in PubMed: www.ncbi.nlm.nih.gov/pubmed/3775315

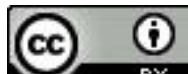




\title{
Follow-up study of patients with vibration syndrome in Japan
}

\author{
by Yoshiro Nasu, MD, ${ }^{1}$ Kazuo Ishida, $M^{2}$
}

\begin{abstract}
NASU Y, ISHIDA K. Follow-up study of patients with vibration syndrome in Japan. Scand $J$ Work Environ Health 12 (1986) 313-319. This study was performed on 187 patients with vibration syndrome treated and followed for more than five years in 10 hospitals in Japan. The subjects had disturbances of circulation and sensation in their fingers and of joint movements in their upper extremities. Most of the patients received treatment combining physical and drug therapy. Data were analyzed to determine the effective treatment period for improving the disturbances. The blanching attack (Raynaud's phenomenon) and abnormal cold and tingling sensations in the fingers were significantly improved only during the first two years of treatment. A temperature test and plethysmography suggested improvement in finger circulation only during the first three years and one year of treatment, respectively. Spontaneous numbness and pain in the fingers did not improve. The pin-prick and vibratory sensations showed recovery only during the first three and two years of treatment, respectively. Lowered conduction velocities cf the ulnar and median nerves improved only during the first year. Limited movements in the wrist and elbow joints did not improve at all despite long-term treatment. Similar results were seen in an overall evaluation of the data. It was concluded that there is a limitation in the treatment of disturbances related to the vibration syndrome.
\end{abstract} Key terms: limitation of improvement, musculoskeletal disturbance, peripheral circulatory disturbance,
peripheral nerve disturbance.

Several decades have passed since the initiation of therapy for patients with vibration syndrome in Japan. However data on the overall results of the treatment are not yet available. The aim of the present study is to evaluate the efficacy of therapy by analyzing the data from 187 patients with vibration syndrome in this country.

\section{Subjects}

Data were collected from 187 patients who received medical treatment for vibration syndrome for more than five years in 10 hospitals in this country and who could be followed up annually for more than five years after the beginning of treatment. All of these patients were freed from work with vibrating tools after they were diagnosed as suffering from vibration syndrome. The nature of their occupations, the types of vibrating tools, the average age at the beginning of treatment, and the average periods from the cessation of the use of vibrating tools to the beginning of treatment and to the start of the follow-up study are shown in table 1.

The severity of the vibration syndrome was classified into four stages determined before the beginning of therapy rather than each year during the follow-up study. Stage I was characterized by subjective symptoms such as intermittent tingling and numbness in fingers in winter, but by no episode of Raynaud's

1 Department of Orthopedic Surgery, San-in Rosai Hospital, 1480 Kaike, Yonago 683, Japan.

2 Department of Surgery, Yamaguchi Rosai Hospital, 1315-4 Onoda, Onoda 756, Japan.

Reprint requests to: Dr Y Nasu, Department of Orthopedic Surgery, San-in Rosai Hospital, 1480 Kaike, Yonago 683,
Japan. phenomenon. Cold provocation and nail compression tests also showed slight recovery to the normal range in the skin temperature and nail color, respectively, of the fingers. Stage II comprised complaints of con-

Table 1. Profile of the patients with vibration syndrome. ${ }^{a}$

\begin{tabular}{lrr}
\hline Characteristic & $\begin{array}{c}\text { Number } \\
\text { of } \\
\text { cases }\end{array}$ & Percentage \\
\hline Industry & & \\
National forest worker & 90 & 48.1 \\
Private forest worker & 74 & 39.6 \\
Mining industry & 7 & 3.7 \\
Stone quarrying industry & 1 & 0.5 \\
Construction industry & 3 & 1.6 \\
Manufacturing industry & 10 & 5.4 \\
Others & 2 & 1.1 \\
Total & 187 & 100.0 \\
Types of vibrating tools & & \\
Chain saws & 152 & 77.2 \\
Jack hammer & 11 & 5.6 \\
Pick hammer & 6 & 3.1 \\
Bush cleaner & 12 & 6.1 \\
Chipping hammer & 5 & 2.5 \\
Grinder & 8 & 4.0 \\
Others & 3 & 1.5 \\
Total & 197 & 100.0 \\
Period of the use of & & \\
vibrating tools (years) & & \\
< 3 & 6 & 3.2 \\
$3-5$ & 20 & 11.7 \\
$5-10$ & 62 & 33.2 \\
10-20 & 88 & 47.1 \\
O-20 & 10 & 5.4 \\
Unknown & 1 & 0.5 \\
Total & 187 & 100.0 \\
\hline Average & & \\
\hline
\end{tabular}

a Average age at beginning of therapy 48.8 (SD 7.4) years; average period from cessation of using vibrating tools to beginning of therapy 1.4 (SD 23.0) months; average period from cessation of using vibrating tools to start of the followup study 99.4 (SD 43.8) months. 
Table 2. Classification of severity of symptoms and objective findings of the vibration syndrome.

\begin{tabular}{|c|c|c|c|c|}
\hline & Grade I & Grade II & Grade III & Grade IV \\
\hline \multicolumn{5}{|l|}{ Disturbance in peripheral circulation } \\
\hline Raynaud's phenomenon & $\begin{array}{l}\text { No appear- } \\
\text { ance }\end{array}$ & Sometimes & Frequently & Throughout the year \\
\hline $\begin{array}{l}\text { Cold and tingling sensation in } \\
\text { fingers }\end{array}$ & $\begin{array}{l}\text { No appear- } \\
\text { ance }\end{array}$ & Intermittent & $\begin{array}{l}\text { Continuous for } \\
\text { a limited time }\end{array}$ & Always \\
\hline $\begin{array}{l}\text { Overall evaluation of the subjective } \\
\text { symptoms }\end{array}$ & Normal & Slightly abnormal & Moderately abnormal & Very abnormal \\
\hline \multicolumn{5}{|l|}{ Skin temperature test } \\
\hline $\begin{array}{l}\text { At rest } \\
\text { After cold provocation }\end{array}$ & $\begin{array}{l}\text { Normal } \\
\text { Normal } \\
\text { recovery }\end{array}$ & $\begin{array}{l}\text { Slightly abnormal } \\
\text { Slightly delayed } \\
\text { recovery }\end{array}$ & $\begin{array}{l}\text { Moderately abnormal } \\
\text { Moderately delayed } \\
\text { recovery }\end{array}$ & $\begin{array}{l}\text { Very abnormal } \\
\text { Very delayed } \\
\text { recovery }\end{array}$ \\
\hline \multicolumn{5}{|l|}{ Nail compression test } \\
\hline $\begin{array}{l}\text { At rest } \\
\text { After cold provocation }\end{array}$ & $\begin{array}{l}\text { Normal } \\
\text { Normal } \\
\text { recovery }\end{array}$ & $\begin{array}{l}\text { Slightly abnormal } \\
\text { Slightly delayed } \\
\text { recovery }\end{array}$ & $\begin{array}{l}\text { Moderately abnormal } \\
\text { Moderately delayed } \\
\text { recovery }\end{array}$ & $\begin{array}{l}\text { Very abnormal } \\
\text { Very delayed } \\
\text { recovery }\end{array}$ \\
\hline $\begin{array}{l}\text { Finger plethysmography } \\
\text { (patterns of arch and plateau } \\
\text { waves) }\end{array}$ & Normal & Sometimes & Frequently & Throughout the year \\
\hline $\begin{array}{l}\text { Overall evaluation of the } \\
\text { objective findings }\end{array}$ & Normal & Slightly abnormal & Moderately abnormal & Very abnormal \\
\hline \multicolumn{5}{|l|}{$\begin{array}{l}\text { Disturbance in the peripheral } \\
\text { nervous system }\end{array}$} \\
\hline Sensory disturbance ${ }^{a}$ & Without & Slightly abnormal & Moderately abnormal & Very abnormal ${ }^{b}$ \\
\hline Numbness and pain in the fingers & Without & Intermittent & $\begin{array}{l}\text { Continuous for a } \\
\text { limited time }\end{array}$ & Always \\
\hline $\begin{array}{l}\text { Overall evaluation of the } \\
\text { subjective symptoms }\end{array}$ & Normal & Slightly abnormal & Moderately abnormal & Very abnormal \\
\hline \multicolumn{5}{|l|}{ Pain sensation (pin-prick test) } \\
\hline $\begin{array}{l}\text { At rest } \\
\text { After cold provocation }\end{array}$ & $\begin{array}{l}\text { Normal } \\
\text { Normal }\end{array}$ & $\begin{array}{l}\text { Slightly abnormal } \\
\text { Slightly abnormal }\end{array}$ & $\begin{array}{l}\text { Moderately abnormal } \\
\text { Moderately abnormal }\end{array}$ & $\begin{array}{l}\text { Very abnormal } \\
\text { Very abnormal }\end{array}$ \\
\hline \multicolumn{5}{|l|}{ Vibratory sensation } \\
\hline $\begin{array}{l}\text { At rest } \\
\text { After cold provocation }\end{array}$ & $\begin{array}{l}\text { Normal } \\
\text { Normal }\end{array}$ & $\begin{array}{l}\text { Slightly abnormal } \\
\text { Slightly abnormal }\end{array}$ & $\begin{array}{l}\text { Moderately abnormal } \\
\text { Moderately abnormal }\end{array}$ & $\begin{array}{l}\text { Very abnormal } \\
\text { Very abnormal }\end{array}$ \\
\hline Nerve conduction velocity & Normal & Slightly abnormal & Moderately abnormal & Very abnormal \\
\hline $\begin{array}{l}\text { Overall evaluation of objective } \\
\text { findings }\end{array}$ & Normal & Slightly abnormal & Moderately abnormal & Very abnormal \\
\hline \multicolumn{5}{|l|}{$\begin{array}{l}\text { Disturbance in the } \\
\text { musculoskeletal system }\end{array}$} \\
\hline \multicolumn{5}{|l|}{ Pain in joint during motion } \\
\hline Right wrist & Without & $\begin{array}{l}\text { Beginning of } \\
\text { appearance of pain }\end{array}$ & $\begin{array}{l}\text { Continuous pain } \\
\text { (always) }\end{array}$ & $\begin{array}{l}\text { Severe pain } \\
\text { (always) }\end{array}$ \\
\hline Left wrist & Without & $\begin{array}{l}\text { Beginning of } \\
\text { appearance of pain }\end{array}$ & $\begin{array}{l}\text { Continuous pain } \\
\text { (always) }\end{array}$ & $\begin{array}{l}\text { Severe pain } \\
\text { (always) }\end{array}$ \\
\hline Right elbow & Without & $\begin{array}{l}\text { Beginning of } \\
\text { appearance of pain }\end{array}$ & $\begin{array}{l}\text { Continuous pain } \\
\text { (always) }\end{array}$ & $\begin{array}{l}\text { Severe pain } \\
\text { (always) }\end{array}$ \\
\hline Left elbow & Without & $\begin{array}{l}\text { Beginning of } \\
\text { appearance of pain }\end{array}$ & $\begin{array}{l}\text { Continuous pain } \\
\text { (always) }\end{array}$ & $\begin{array}{l}\text { Severe pain } \\
\text { (always) }\end{array}$ \\
\hline \multicolumn{5}{|l|}{ Range of motion in the joint } \\
\hline Right wrist & Normal & $\begin{array}{l}\text { Limitation less than } \\
\text { three-fourths of normal }\end{array}$ & $\begin{array}{l}\text { Limitation less than } \\
\text { one-half of normal }\end{array}$ & $\begin{array}{l}\text { Limitation more than } \\
\text { one-half of normal }\end{array}$ \\
\hline Left wrist & Normal & $\begin{array}{l}\text { Limitation less than } \\
\text { three-fourths of normal }\end{array}$ & $\begin{array}{l}\text { Limitation less than } \\
\text { one-half of normal }\end{array}$ & $\begin{array}{l}\text { Limitation more than } \\
\text { one-half of normal }\end{array}$ \\
\hline Right elbow & Normal & $\begin{array}{l}\text { Limitation less than } \\
\text { three-fourths of normal }\end{array}$ & $\begin{array}{l}\text { Limitation less than } \\
\text { one-half of normal }\end{array}$ & $\begin{array}{l}\text { Limitation more than } \\
\text { one-half of normal }\end{array}$ \\
\hline Left elbow & Normal & $\begin{array}{l}\text { Limitation less than } \\
\text { three-fourths of normal }\end{array}$ & $\begin{array}{l}\text { Limitation less than } \\
\text { one-half of normal }\end{array}$ & $\begin{array}{l}\text { Limitation more than } \\
\text { one-half of normal }\end{array}$ \\
\hline \multicolumn{5}{|l|}{ Delayed uinar palsy } \\
\hline $\begin{array}{l}\text { Right side } \\
\text { Left side }\end{array}$ & $\begin{array}{l}\text { Normal } \\
\text { Normal }\end{array}$ & $\begin{array}{l}\text { Only numbness } \\
\text { Only numbness }\end{array}$ & $\begin{array}{l}\text { Moderate } \\
\text { Moderate }\end{array}$ & $\begin{array}{l}\text { Typical } \\
\text { Typical }\end{array}$ \\
\hline
\end{tabular}

a For example hypesthesia or hypalgesia.

b Typical glove type of sensory disturbance.

tinuous tingling, pain, numbness, and stiffness of the fingers in winter and an occasional occurrence of Raynaud's phenomenon. Cold provocation and nail compression tests also showed delayed recovery of the skin temperature and nail color. Patients in stage III had the aforementioned subjective symptoms and also a frequent occurrence of Raynaud's phenomenon. The cold provocation tests showed abnormal delayed 
recovery of skin temperature and nail color. Stage IV involved severe coldness, tingling, pain, and severe numbness of the fingers. A typical glove type of sensory disturbance was observed, and Raynaud's phenomenon occurred frequently throughout the year. The cold provocation tests showed very delayed, abnormal recovery of the skin temperature and nail color. Of the 187 cases, 23 were classed as stage I, 92 as stage II, 67 as stage III, and 5 as stage IV.

\section{Methods}

This was a retrospective study, using a questionnaire about subjective symptoms, objective findings, period of use of vibrating tools, methods of treatment, occupation, etc. The questionnaire for each patient, completed by the physicians in charge, was collected every year for five years after the beginning of the therapy. The answers on the questionnaire were investigated and major items, ie, disturbances of peripheral circulation, the peripheral nervous system, and musculoskeletal system of the upper extremities, were statistically analyzed. The severity of a number of subjective symptoms and objective findings were classified into four grades as shown in table 2 . The classifications were made by specialists experienced with the diagnosis and treatment of patients with vibration syndrome.

To evaluate the degree of improvement in the subjective symptoms and objective findings by treatment, a chi-square test was used. Table 3 shows an example of the improvement in Raynaud's phenomenon.

\section{Results}

The results obtained are summarized in table 4 .

\section{Peripheral circulatory disturbance}

The number of cases classified as grade I of Raynaud's phenomenon and the summed numbers of cases classified as grade I and II were significantly increased during the first two and one years, respectively, after the beginning of therapy. On the other hand, the number of cases classified as grade IV did not significantly change in spite of treatment. Therefore, the period of two years was regarded as the maximal effective period of treatment to produce significant improvement in the occurrence of Raynaud's phenomenon. With respect to the cold and tingling sensations in the fingers, the effective period for improvement was two years. The overall evaluation of improvement in the aforementioned subjective symptoms of peripheral circulatory disturbances suggested that the effective period for significant improvement was two years.

The effective period of treatment for improvement in skin temperature at rest was three years. On the other hand, as determined from the data of the cold provocation test, it was two years. The effective treatment periods for improvement in nail compression at rest and after cold provocation were two and

Table 3. Improvement in Raynaud's phenomenon.

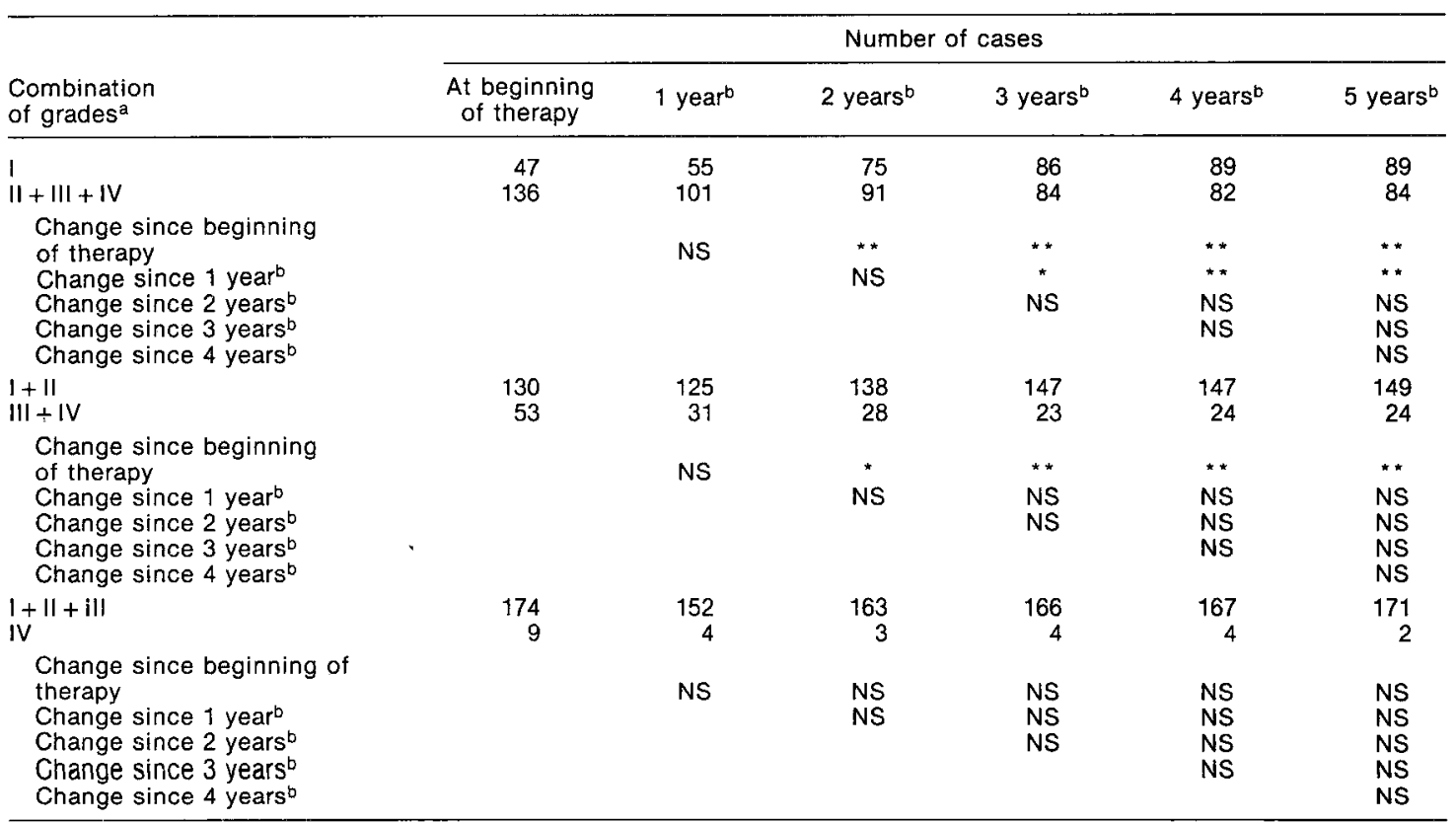

a For a definition of the grades, see table 2.

b After the beginning of therapy.

${ }^{*} p<0.01,{ }^{* \star} p<0.005$, NS = not significant. 
Table 4. Improvement in subjective symptoms and objective findings of the vibration syndrome.

\begin{tabular}{|c|c|c|c|}
\hline & \multicolumn{3}{|c|}{ Combination of grades ${ }^{a, b}$} \\
\hline & (I):(II + III + IV) & $(I+I I):(I I I+I V)$ & $(I+I I+I I I):(I V)$ \\
\hline \multicolumn{4}{|l|}{ Peripheral circulatory disturbance } \\
\hline $\begin{array}{l}\text { Raynaud's phenomenon } \\
\text { Cold and tingling sensation }\end{array}$ & $\begin{array}{l}2 \\
1\end{array}$ & $\begin{array}{l}1 \\
2\end{array}$ & $\overline{-}$ \\
\hline Overall evaluation of the subjective symptoms & 2 & 2 & 1 \\
\hline \multicolumn{4}{|l|}{ Skin temperature test } \\
\hline $\begin{array}{l}\text { At rest } \\
\text { After cold provocation }\end{array}$ & 3 & 2 & 1 \\
\hline \multicolumn{2}{|l|}{ Nail compression test } & 2 & 2 \\
\hline At rest & 2 & 2 & - \\
\hline After cold provocation & 4 & 4 & - \\
\hline Finger plethysmography & 1 & 1 & - \\
\hline Overall evaluation of the objective findings & 3 & 4 & 1 \\
\hline \multicolumn{4}{|l|}{ Disturbance of the peripheral nervous system } \\
\hline $\begin{array}{l}\text { Sensory disturbance } \\
\text { Numbness and pain sensation }\end{array}$ & - & - & - \\
\hline Overall evaluation of the subjective symptoms & - & - & - \\
\hline \multicolumn{4}{|l|}{ Pin-prick sensation } \\
\hline At rest & 1 & - • & 3 \\
\hline After cold provocation & 2 & $\overline{1}$ & $\underline{3}$ \\
\hline \multicolumn{4}{|l|}{ Vibratory sensation } \\
\hline $\begin{array}{l}\text { At rest } \\
\text { After cold provocation }\end{array}$ & 1 & - & 1 \\
\hline $\begin{array}{l}\text { After cold provocation } \\
\text { Nerve conduction velocity }\end{array}$ & $\overline{1}$ & 2 & 2 \\
\hline Overall evaluation of the objective findings & 1 & - & $\bar{c}$ \\
\hline \multirow{2}{*}{\multicolumn{4}{|c|}{ Disturbance of the musculoskeletal system }} \\
\hline \multirow{2}{*}{\multicolumn{4}{|c|}{ Pain in the wrist joint }} \\
\hline $\begin{array}{l}\text { Pain in the wrist joint } \\
\text { Right }\end{array}$ & & & \\
\hline Left & 3 & 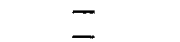 & 二 \\
\hline \multicolumn{4}{|l|}{ Pain in the elbow joint } \\
\hline Right & - & - & - \\
\hline Left & - & - & - \\
\hline \multicolumn{4}{|l|}{ Delayed ulnar palsy } \\
\hline $\begin{array}{c}\text { Right } \\
\text { Left }\end{array}$ & - & - & - \\
\hline \multicolumn{4}{|l|}{ Range of motion of the wrist joint } \\
\hline Right & - & - & - \\
\hline Left & - & - & - \\
\hline \multicolumn{4}{|l|}{ Range of motion of the elbow joint } \\
\hline $\begin{array}{l}\text { Right } \\
\text { Left }\end{array}$ & $\overline{-}$ & $\overline{-}$ & $\overline{-}$ \\
\hline
\end{tabular}

a For a definition of the grades, see table 2 .

b Numbers of years of treatment rieeded to obtain statistically significant improvement are presented. (-indicates no improvement)

four years, respectively. The effective treatment period for significant improvement in finger circulation, determined by finger plethysmography, was only one year. The overall evaluation of these objective findings suggested that the period for improvement in peripheral circulatory disturbances related to vibration syndrome was four years.

\section{Peripheral nerve disturbances}

The sensory disturbances, the sensation of numbness and pain, and the overall evaluation of these subjective symptoms showed no significant improvement in spite of long-term treatment.

The period of treatment for effective improvement in abnormal pain sensation at rest was three years. Effective periods for the recovery of the pin-prick sensation after cold provocation, the vibratory sensation at rest, and the vibratory sensation after cold provocation were two, one, and two years, respectively. Lowered conduction velocities of the ulnar and median nerves improved only during the first year. The overall evaluation of these objective findings revealed that the treatment period for the improvement of peripheral nerve disturbances was three years at the maximum.

\section{Musculoskeletal disturbance}

No significant improvement was observed in the musculoskeletal disturbances, except for pain in the joint of the left wrist.

Comparison of therapeutic results among patients with the different stages of severity of vibration syndrome

Table 5 shows the therapeutic results of subjective symptoms and objective findings for the stages of severity of vibration syndrome.

As the result of treatment, there was no significant improvement in subjective symptoms and objective 
Table 5. Improvement in the subjective symptoms and objective findings according to the stages of severity of the vibration syndrome. ${ }^{a}$

Stages of severity of the vibration syndrome

\begin{tabular}{lll}
\hline$(I):(I I+I I I+I V)$ & $(I+I I):(I I I+I V)$ & $(I+I I+I I I):(I V)$ \\
\hline
\end{tabular}

Disturbance in peripheral circulation

Raynaud's phenomenon

Grade I

Grade II

Grade III

Grade IV

Cold and tingling sensation

Grade 1

Grade II

Grade III

Grade IV

Overall evaluation the subjective symptoms of disturbances in peripheral circulation

$$
\begin{aligned}
& \text { Grade I } \\
& \text { Grade II } \\
& \text { Grade III } \\
& \text { Grade IV }
\end{aligned}
$$

Skin temperature test

At rest

Grade I

Grade II

Grade III

Grade IV

After cold provocation

Grade I

Grade II

Grade II

Grade IV

Nail compression test

At rest

Grade I

Grade II

Grade III

Grade IV

After cold provocation

Grade I

Grade II

Grade III

Grade IV

Finger plethysmography

Grade I

Grade II

Grade III

Grade IV

Overall evaluation of the objective findings of

disturbances in peripheral circulation

Grade I

Grade II

Grade III

Grade IV

Disturbance in the peripheral nervous system

Sensory disturbance

Grade I

Grade II

Grade III

Grade IV

Numbness and pain in the fingers

Grade I

Grade II

Grade III

Grade IV

Overall evaluation of the subjective symptoms

of disturbances in the peripheral nervous system

Grade I

Grade II

Grade III

Grade IV

1
2
2

-

$\overline{1}$

$-$

1

$\underline{-}$

3

1

$\overrightarrow{1}$

-

-
1

1 $\overline{-}$

$\frac{-}{1}$

$-$

1

-

$\frac{-}{2}$

$=$
$=$
$=$
$=$
-
$\overline{1}$

$\frac{-}{2}$

-
-
-
-
-

-

(continued) 
Table 5. Continued.

\begin{tabular}{|c|c|c|c|}
\hline & \multicolumn{3}{|c|}{ Stages of severity of the vibration syndrome } \\
\hline & $(I):(I I+I I I+I V)$ & $(I+I I):(I I I+I V)$ & $(I+I I+I I I):(I V)$ \\
\hline \multicolumn{4}{|l|}{ Pain sensation } \\
\hline \multicolumn{4}{|l|}{ At rest } \\
\hline Grade I & 2 & - & - \\
\hline Grade II & - & - & $\overline{2}$ \\
\hline Grade III & - & 1 & - \\
\hline Grade IV & - & - & - \\
\hline \multicolumn{4}{|c|}{ After cold provocation } \\
\hline Grade I & 2 & - & - \\
\hline Grade II & 1 & - & - \\
\hline $\begin{array}{l}\text { Grade III } \\
\text { Grade IV }\end{array}$ & - & - & - \\
\hline \multicolumn{4}{|c|}{ Vibratory sensation } \\
\hline \multicolumn{4}{|c|}{ At rest } \\
\hline Grade I & 1 & - & - \\
\hline Grade II & - & - & - \\
\hline Grade III & - & - & - \\
\hline Grade IV & - & - & - \\
\hline \multicolumn{4}{|c|}{ After cold provocation } \\
\hline Grade I & - & - & - \\
\hline Grade II & - & - & 2 \\
\hline Grade III & - & 2 & 2 \\
\hline \multirow{2}{*}{\multicolumn{4}{|c|}{ Nerve conduction velocity }} \\
\hline & & & \\
\hline Grade I & - & - & - \\
\hline Grade II & - & - & - \\
\hline Grade III & - & - & - \\
\hline \multicolumn{4}{|c|}{$\begin{array}{l}\text { Overall evaluation of the objective findings of } \\
\text { disturbances in the peripheral nervous system }\end{array}$} \\
\hline Grade I & 2 & - & - \\
\hline Grade II & 1 & - & 2 \\
\hline Grade III & - & - & 2 \\
\hline Grade IV & - & - & - \\
\hline
\end{tabular}

a For a definition of the grades see table 2; for an explanation of the stages, see the text.

findings in the musculoskeletal system $(5 \%$ level of probability). There was also no significant improvement in objective findings and subjective symptoms related to both peripheral circulatory and peripheral nerve disturbances for cases in stage IV.

With respect to subjective symptoms related to peripheral circulatory disturbance, the maximum effective period of treatment to produce significant improvement was one year for stage I, three years for stage II, and two years for stage III. As to objective findings of the disturbance, the maximum effective period for improvement was four years for stage I and II and three years for stage III.

Concerning the subjective symptoms related to peripheral nerve disturbance, the maximum effective period for significant improvement was two years for stage II. Stage I and III showed no significant improvement. With respect to objective findings of peripheral nerve disturbance, the longest period for significant improvement was two years for stages I, II, and III.

\section{Discussion}

The effective period of treatment for significant improvement in both Raynaud's phenomenon and ab- normal cold and tingling sensation in the fingers was two years in the present study. The overall evaluation of the subjective symptoms revealed that the effective treatment period for peripheral circulatory disturbances was two years. On the other hand, the effective periods for significant improvement in peripheral circulatory disturbances determined by the skin temperature test, nail compression test, and finger plethysmography were three, four, and one year, respectively. The overall evaluation of the objective findings disclosed that the effective period for peripheral circulatory disturbances was in a similar range of four years. Therefore, the maximum effective period was considered to be four years for improvement in objective and subjective peripheral circulatory disturbances. The maximum effective period for improvement in subjective and objective disturbance of the peripheral nervous system was also in this range. With respect to musculoskeletal disturbances, no statistically significant improvement was observed, except for pain in the joint of the left wrist. This exception could not be explained, because the joint pain was úsually caused by degenerative changes in most cases.

On the basis of these results, it can be concluded that four years of treatment is necessary and sufficient 
for significant improvement in most of the subjective and objective disturbances that are a part of the vibration syndrome. After this treatment period any remaining subjective symptoms and abnormal findings must be considered as sequelae. It can be also concluded that, with respect to peripheral circulatory disturbances, subjective symptoms improve earlier than objective findings.

With respect to disturbances of the peripheral nervous system, no significant improvement in subjective symptoms was observed, although some objective findings showed improvement. The maximum effective periods of treatment for improvement of pin-prick and vibratory sensations at rest were shorter than those for improvement in the cold provocation tests. There were many cases with normal skin temperature of the fingers at rest, but with a very delayed recovery of skin temperature after cold provocation. Furthermore numbness in the fingers was improved, even though only temporarily, by an intraarterial injection of reserpine. These results suggest that peripheral nerve disturbances are partially related to peripheral circulatory disturbances.

In the comparison of the improvement of stages I through IV of the vibration syndrome, the maximum effective period of treatment tended to be shorter for cases in stage I than for those of stages II and III, probably because the subjective symptoms and objective findings of the cases in stage I were nearly normal. Concerning peripheral circulatory disturbances, the maximum effective period of treatment of cases in stage II was three years for subjective symptoms and four years for objective findings. The period for cases in stage III was two years for subjective symptoms and three years for objective findings. With respect to the peripheral nerve disturbance, the maximum effective periods of treatment of cases in stage II were two years for subjective symptoms and two years for objective findings. The corresponding period for cases in stage III were zero for subjective symptoms and two years for objective findings. These differences were thought to be due to differences in the severity of the vibration syndrome between stage II and III. Although there were only five cases in stage IV, a statistical analysis was tentatively made for the findings of these cases. No significant improvement in subjective and objective findings was observed. This result was confirmed by another study, in which the same analysis was made on 17 cases in stage IV, including the five cases of the present study. Whether pathophysiological and pathomorphological changes in the cases in stage IV are irreversible or unresponsive to the usual methods of medical treatment could not be determined from the results of our study because the number of cases classified as stage IV was relatively small.

We could not determine the most effective methods or drugs for treating the disturbances related to vibration syndrome because all of the cases were treated with a combination of several kinds of physical therapy, such as paraffin bath, hot pack, hot spring bath, and gymnastics, in association with the administration of many kinds of vasoactive drugs; and the therapeutic effects of individual physical therapies or drugs could not be differentiated.

In cases in stage I, II, III, and IV there was no significant improvement in the subjective symptoms and objective findings of musculoskeletal disturbances, in spite of long-term treatment. This result was in clear contrast to significant improvement in the peripheral circulatory and peripheral nerve disturbances.

\section{Acknowledgments}

The authors are grateful to Drs N Kiyota, T Oku, W Suzuki, G Ichinomiya, T Mishima, H Osako, K Habu, and T Matoba for their assistance in this study. We also thank Dr H Shingu for his continuous encouragement throughout the course of this study and valuable criticism during the preparation of the manuscript. 